九州大学学術情報リポジトリ

Kyushu University Institutional Repository

Is lateral acetabular rotation sufficient to correct anterolateral deficiency in periacetabular reorientation osteotomy? A CTBased simulation study

ht tp://hdl. hand le. net/2324/4110400

出版情報: 九州大学，2020，博士（医学），課程博士 バージョン:

権利関係: (c)2020 The Japanese Orthopaedic Association. Published by Elsevier B.V. All rights reserved. 
Original Article

\title{
Is lateral acetabular rotation sufficient to correct anterolateral deficiency in periacetabular reorientation osteotomy? A CT-Based simulation study
}

\author{
Miho Iwamoto, Masanori Fujii , Keisuke Komiyama, Yuta Sakemi, Kyohei Shiomoto, \\ Kenji Kitamura, Ryosuke Yamaguchi, Yasuharu Nakashima \\ Department of Orthopaedic Surgery, Graduate School of Medical Sciences, Kyushu University, 3-1-1 Maidashi, Higashi-ku, Fukuoka 812-8582, Japan
}

\section{A R T I C L E I N F O}

\section{Article history:}

Received 2 October 2019

Received in revised form

27 November 2019

Accepted 28 December 2019

Available online $\mathrm{xxx}$

\begin{abstract}
A B S T R A C T
Background: Residual acetabular deficiency after periacetabular reorientation osteotomy can result in suboptimal outcome. The optimal algorithm of acetabular fragment correction to achieve normal anterolateral acetabular coverage is not well characterized. The aim of this study was to determine the prevalence of residual anterolateral deficiency after lateral acetabular rotation and to evaluate the ability of additional sagittal and axial rotation of the acetabulum to normalize the acetabular coverage in periacetabular osteotomy.

Methods: We performed computed tomography-based simulated periacetabular osteotomy on 85 patients (85 hips) with hip dysplasia. The acetabular fragment was rotated laterally to achieve a lateral center-edge angle (CEA) of $30^{\circ}$. For hips with residual anterolateral deficiency, which were identified based on the reference interval of the anterior CEA, the acetabulum was further rotated in the sagittal or axial direction in 5-degree increments from $5^{\circ}$ to $20^{\circ}$, and the ability of these two manoeuvres to restore a normal anterior CEA was assessed.

Results: After lateral acetabular rotation, 16 hips (19\%) had residual anterolateral deficiency, 67 hips (79\%) had normal acetabular coverage, and 2 hips $(2.4 \%)$ had acetabular overcoverage. A preoperative anterior CEA $<37^{\circ}$ predicted residual deficiency (sensitivity, 94\%; specificity, $81 \%$ ). Additional anterior sagittal rotation was more effective than posterior axial rotation in normalizing the anterior CEA, while minimizing the decrease in posterior CEA. The highest number of hips with normal anterior and posterior CEA was noted at $10^{\circ}$ sagittal rotation (81\%), which was followed by $15^{\circ}$ sagittal rotation (63\%).

Conclusions: Normal anterolateral coverage was achieved in $79 \%$ of patients after rotating the acetabulum laterally. However, lateral rotation of the acetabulum may be insufficient to correct the anterolateral deficiency in patients with an anterior CEA of $<37^{\circ}$. In them, additional $10^{\circ}-15^{\circ}$ anterior sagittal rotation may be appropriate to achieve sufficient anterolateral coverage while retaining posterolateral coverage.

() 2020 The Japanese Orthopaedic Association. Published by Elsevier B.V. All rights reserved.
\end{abstract}

\section{Introduction}

Periacetabular reorientation osteotomies have been developed for young adult patients with symptomatic hip dysplasia to delay or prevent subsequent hip osteoarthritis (OA) [1,2]. A common aim of these osteotomies is to correct abnormal hip biomechanics by increasing the femoral head coverage by a three-dimensional (3D) acetabular correction. The outcomes of these osteotomies, although generally favourable, could be affected by various factors including

\footnotetext{
* Corresponding author. Fax: +81926425507.

E-mail address: m-fujii@ortho.med.kyushu-u.ac.jp (M. Fujii).
}

suboptimal correction [3], and acetabular deformity varies between individuals. Thus, a 3D morphological evaluation using computed tomography (CT) is recommended to customize the acetabular correction accordingly [2,4-7].

Hip dysplasia typically manifests with anterolateral acetabular deficiency [4,5], in which shearing stress force and overload are concentrated on the anterolateral acetabular rim [8]. Thus, the intra-articular pathology generally originates from the anterolateral labro-chondral junction of the acetabulum [9]. Therefore, an adequate correction of the anterolateral acetabular deficiency is crucial for a successful hip preservation [10]. During the reorientation process, the first step is to achieve sufficient lateral 
coverage by lateral rotation of the acetabular fragment, and the second step is to achieve a sufficient anterior coverage by anterior rotation [11]. An alternative correction manoeuvre is to decrease acetabular anteversion. However, the effects of sagittal and axial rotations of the acetabular fragment on the 3D acetabular coverage have not been well characterised, and controversies regarding the optimal algorithm for acetabular correction to achieve a normal acetabular coverage exist.

While anterolateral rotation of the acetabular fragment has been suggested to be more effective in reducing contact pressure than lateral rotation alone [12], some studies reported that anterior and lateral subluxations could be improved by lateral rotation only [13]. In addition, careful attention is needed when performing anterior rotation because it may result in excessive anterolateral coverage and anterior mismatch between the acetabulum and femoral neck, which could in turn lead to secondary femoroacetabular impingement [14]. Moreover, inadequate anterior acetabular rotation could worsen posterior wall deficiency, causing possible development of posterior hip OA [12,15]. Thus, anterior acetabular rotation should be performed only in patients with residual anterolateral deficiency after lateral acetabular rotation.

Currently, a defining characteristic of patients at risk for residual anterolateral deficiency after lateral acetabular rotation is lacking, and if additional correction is needed after lateral rotation, the degree and direction of acetabular correction to normalize the anterior coverage remain to be identified. Thus, to establish an optimal algorithm for acetabular correction, we sought to determine: (1) the prevalence of residual anterolateral deficiency after lateral acetabular rotation in simulated periacetabular osteotomy; (2) possible predictive factors for residual anterolateral deficiency

Table 1

Demographic and radiographic parameters in hip dysplasia and control groups.

\begin{tabular}{lll}
\hline Parameter & $\begin{array}{l}\text { Hip dysplasia } \\
(\mathrm{n}=85 \mathrm{hips})\end{array}$ & $\begin{array}{l}\text { Control } \\
(\mathrm{n}=50 \text { hips })\end{array}$ \\
\hline $\begin{array}{l}\text { Demographic parameters } \\
\text { Age (years) }\end{array}$ & $38(13-57)$ & $33(26-48)$ \\
$\quad$ Sex & & \\
$\quad$ Male & 0 & 0 \\
$\quad$ Female & $85(100 \%)$ & $25(100 \%)$ \\
$\quad$ Body mass index $\left(\mathrm{kg} / \mathrm{m}^{2}\right)$ & $22(17-35)$ & $20(17-27)$ \\
$\quad$ Weight $(\mathrm{kg})$ & $56(42-95)$ & $52 \pm 6.5$ \\
$\quad$ Height $(\mathrm{cm})$ & $158 \pm 6.5$ & $159 \pm 5.1$ \\
Laterality & & $25(50 \%)$ \\
$\quad$ Right hip & $50(59 \%)$ & $25(50 \%)$ \\
$\quad$ Left hip & $35(21 \%)$ & $29(22-38)$ \\
Radiographic parameters & $14(0-20)$ & \\
Lateral centre-edge angle $\left(^{\circ}\right)$ & &
\end{tabular}

Values are presented as mean \pm standard deviation or median (range).

a Values are presented as number (\%). after simulated osteotomy; and (3) the effect of supplemental sagittal and axial acetabular rotations on the restoration of normal acetabular coverage.

\section{Materials and methods}

\subsection{Patients}

The corresponding institutional review board approved this study. Between January 2010 and January 2019, 144 patients underwent transposition osteotomy of the acetabulum (TOA) [16-18] to treat symptomatic hip dysplasia. Preoperative anteroposterior (AP) pelvic radiographs in the supine position and pelvic CT scans were available for all patients. A total of 137 patients with lateral center-edge angle (CEA) $<20^{\circ}$ of Wiberg [19] were enrolled. Exclusion criteria included advanced OA (Tönnis grade $\geq 2$ ) [20] for either hip joint, other hip disease, prior hip surgery on either hip joint, morphological abnormalities of the femoral head, male sex, and inadequate imaging. Patients with lateral CEA $<0^{\circ}$ were also excluded because their $\mathrm{CT}$ images were unavailable for anterior and posterior CEA measurements. Thirteen patients with advanced OA of the hip, 2 patients with other hip disease, 7 patients with femoral head deformities, 10 male patients, 7 patients with poor quality of imaging, and 13 patients with lateral $\mathrm{CEA}<0^{\circ}$ were excluded. In 31 patients with bilateral hip dysplasia, only the operated side was included in this study. Eighty-five hips of 85 women (hip dysplasia group) were eligible for inclusion (Table 1). The median age at examination was 38 years, and the median lateral CEA was $14^{\circ}$ (range, $0^{\circ}-20^{\circ}$ ). All hips were classified as type I, according to the classification system proposed by Crowe et al. [21]. As controls, we reviewed AP radiographs and pelvic CT scans of 33 healthy female volunteers obtained for the previous study [22]. None had history of disease or articular symptoms in their hips, based on a medical interview and radiographic examination. All subjects provided written informed consent to participate in this study and were informed of the risk of radiation exposure required. Eight subjects with hip dysplasia (lateral CEA $<20^{\circ}$ ) were excluded, thus, 25 subjects (50 hips) were included as control subjects in this study (Table 1). Their supine AP pelvic radiographs and pelvic CT images were obtained using the same protocol as those in the hip dysplasia group. The median age was 33 years, and the median lateral CEA was $29^{\circ}$ (range, $22^{\circ}-38^{\circ}$ ).

\subsection{Computed tomography measurements}

Pelvic CT images (Aquilion; Toshiba, Tochigi, Japan) were acquired at 2.0-mm intervals from the superior pelvic rim to the distal femur with patients in the supine position. After saving the data in
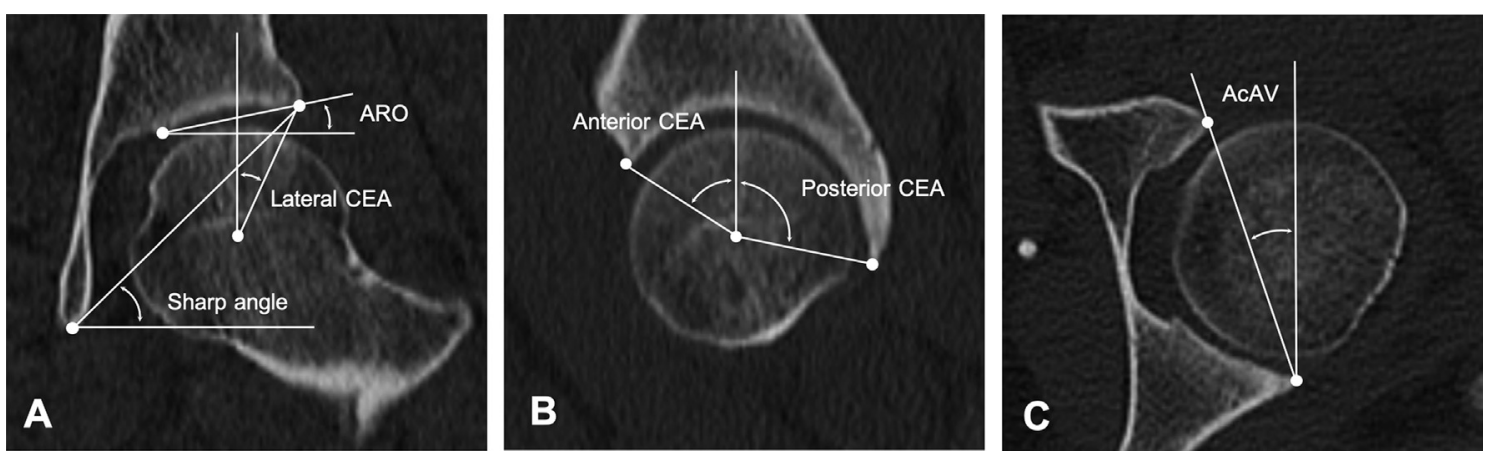

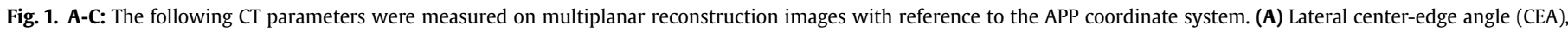
sharp angle, and acetabular roof obliquity (ARO). (B) Anterior and posterior CEAs. (C) Acetabular anteversion angle (AcAV). 
Digital Imaging and Communications in Medicine format (National Electrical Manufacturers Association, Rosslyn, VA, USA), morphological measurements and a simulated periacetabular osteotomy were performed using CT-based simulation software (Zed Osteotomy; Lexi Co., Ltd., Tokyo, Japan). To minimise measurement error, pelvic position was standardised with reference to the anterior pelvic plane (APP) coordinate system [23]. The $\mathrm{x}$-axis was the line connecting the bilateral anterosuperior iliac spines, $y$-axis was perpendicular to the APP, and $z$-axis was perpendicular to the $\mathrm{x}$ and y-axes.

The following CT parameters were measured on multiplanar reconstruction images with reference to the APP coordinate system. On the coronal multiplanar reconstruction view passing through the femoral head center, the lateral centre-edge angle (CEA) was quantified as the angle formed by a line connecting the femoral head center and the lateral edge of the sourcil and the z-axis; the acetabular roof obliquity (ARO), as the angle formed by a line connecting the medial and the lateral edge of the sourcil and the $\mathrm{x}$ axis; and the Sharp angle, as the angle formed by a line connecting the inferior aspect of the teardrop and the lateral edge of the sourcil and the x-axis [24] (Fig. 1A). On the sagittal multiplanar reconstruction view passing through the femoral head center, the anterior CEA was quantified as the angle formed by a line connecting the femoral head center and the anterior edge of the acetabulum and the z-axis and the posterior CEA as the angle formed by a line connecting the femoral head center and the posterior edge of the acetabulum and the z-axis [25] (Fig. 1B). On the axial multiplanar reconstruction view passing through the femoral head center, the acetabular anteversion angle (AcAV) was quantified as the angle formed by a line connecting the anterior and posterior edges of the acetabulum and the y-axis (Fig. 1C). The femoral head diameter was measured as the diameter of a best-fit circle. The femoral anteversion was measured as the angle between the femoral neck axis and the transepicondylar axis according to the method described by Kohno et al. [24]. The measured values in the control subjects were used to calculate the reference interval (mean \pm 1.96 standard deviation) of the parameters (Table 2).

In patients with hip dysplasia, the measurements were performed before and at every step of the acetabular correction during simulated osteotomy. The first author, who was blinded to the clinical results, performed all measurements. In 20 randomly selected hips, measurement reproducibility was tested by two independent observers who repeated the measurements at least 4 weeks apart in a blinded manner. Both intra- and inter-observer measurement reliabilities, which were evaluated using intraclass coefficient, were excellent (range, 0.83-0.99).

\subsection{Simulated acetabular reorientation osteotomy}

TOA, which was first described by Nishio in 1956 [16], is one of the periacetabular reorientation osteotomies characterised by a spherical osteotomy through a lateral approach [17,18]. The osteotomy line, with a radius of $40 \mathrm{~mm}$ in most women patients, typically runs through three points: a point located $2 \mathrm{~cm}$ cranially to the superior joint line on the lateral surface of the ilium, the midpoint between the greater sciatic notch and the posterior edge of the acetabulum, and the innominate sulcus of the ischium. The pubic osteotomy site was located just lateral to the iliopubic tubercle.

Using the Zed Osteotomy software, we performed simulated TOA on 3D surface models of the pelvis, which were reconstructed based on CT images, using a spherical osteotomy line with a radius of $40 \mathrm{~mm}$ around the femoral head center (Fig. 2A). First, the acetabular fragment was rotated laterally (adduction) on the coronal view to achieve a lateral CEA of $30^{\circ}$ (Fig. 2B), which was based
Table 2

Computed tomography measurement parameters and reference intervals in the control group.

\begin{tabular}{lll}
\hline Parameter & Mean \pm SD (range) & $\begin{array}{l}\text { Reference interval } \\
(\text { mean } \pm 1.96 \text { SD) }\end{array}$ \\
\hline Anterior CEA $\left(^{\circ}\right)$ & $53 \pm 5.6$ & $42-64$ \\
Lateral CEA $\left(^{\circ}\right)$ & $30 \pm 4.7$ & $21-40$ \\
Posterior CEA $\left({ }^{\circ}\right)$ & $104 \pm 12$ & $81-128$ \\
Acetabular roof obliquity $\left(^{\circ}\right)$ & $5.1 \pm 4.4$ & -3.5 to 14 \\
Acetabular anteversion angle $\left(^{\circ}\right)$ & $20 \pm 4.4$ & $11-29$ \\
Sharp angle $\left(^{\circ}\right)$ & $42 \pm 3.6$ & $35-49$ \\
Femoral head diameter $(\mathrm{mm})$ & $41 \pm 0.8$ & $39-43$ \\
Femoral anteversion angle $\left(^{\circ}\right)$ & $16 \pm 8.1$ & $0-32$ \\
\hline
\end{tabular}

$\mathrm{CEA}=$ centre-edge angle; $\mathrm{SD}=$ standard deviation

on the mean value of the lateral CEA of the control group (Table 2) and the results of previous studies [25,26]. CT measurements were performed after lateral rotation, and the hip dysplasia group was classified into three groups based on the reference interval of the anterior CEA in the control group (Table 2): residual anterolateral deficiency (anterior CEA $\left.<42^{\circ}\right)$, normal coverage $\left(42^{\circ} \leq\right.$ anterior CEA $<64^{\circ}$ ), and anterolateral overcoverage (anterior CEA $\geq 64^{\circ}$ ) groups. For the residual anterolateral deficiency group, the acetabular fragment was further rotated anteriorly on the sagittal view or posteriorly on the axial view in $5^{\circ}$ increments from $5^{\circ}$ to $20^{\circ}$ to test the ability of sagittal and axial rotations to normalize the anterior acetabular coverage (Fig. 3). In each of these eight acetabular positions, the acetabular coverage was evaluated by measuring the anterior and posterior CEAs.
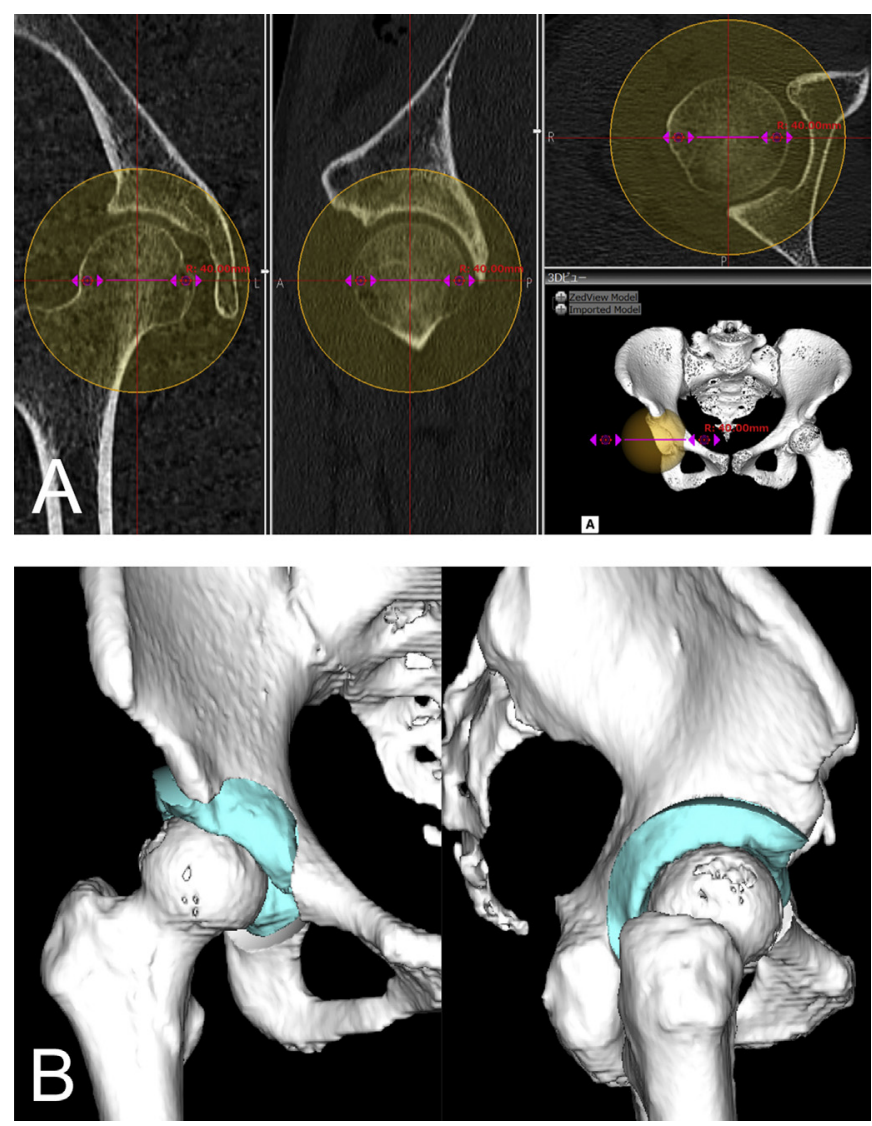

Fig. 2. A-B: (A) A spherical osteotomy line of the simulated periacetabular reorientation osteotomy. (B) The acetabular fragment was rotated laterally to achieve a lateral centre-edge angle of $30^{\circ}$ to restore the normal lateral coverage of the femoral head. 

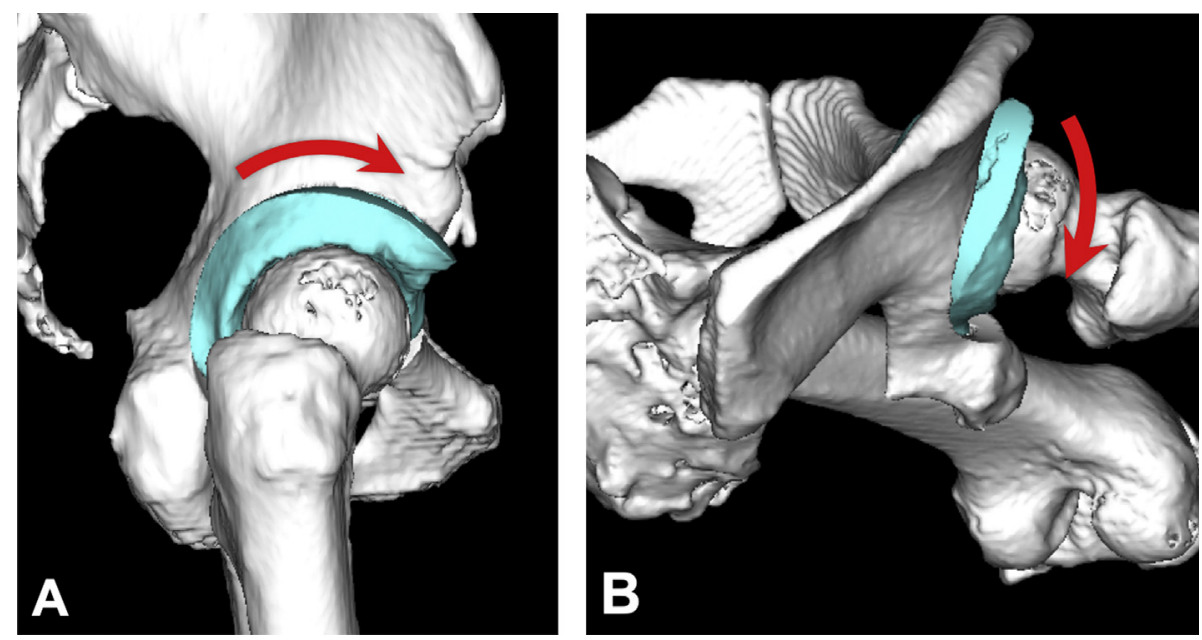

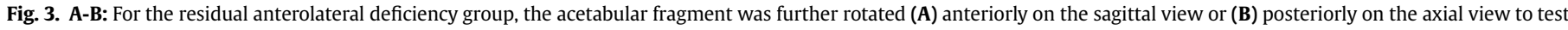
the ability of sagittal and axial rotations to normalise the acetabular coverage of the femoral head.

Table 3

Computed tomography measurement parameters before and after simulated periacetabular reorientation osteotomy in the hip dysplasia group.

\begin{tabular}{llll}
\hline Parameters & Before osteotomy & After osteotomy & p value \\
\hline Anterior CEA $\left(^{\circ}\right)$ & $40(9.7-63)$ & $48 \pm 7.0$ & $<0.001$ \\
Lateral CEA $\left(^{\circ}\right)$ & $15(1.9-24)$ & 30 & $<0.001$ \\
Posterior CEA $\left(^{\circ}\right)$ & $98 \pm 19$ & $96 \pm 12$ & 0.001 \\
ARO $\left(^{\circ}\right)$ & $21 \pm 6.5$ & $5.3 \pm 3.8$ & $<0.001$ \\
AcAV $\left(^{\circ}\right)$ & $24(8.7-41)$ & $29(16-60)$ & $<0.001$ \\
Sharp angle $\left(^{\circ}\right)$ & $49 \pm 3.7$ & $34 \pm 4.9$ & $<0.001$ \\
Femoral head diameter $(\mathrm{mm})$ & $42(38-45)$ & & \\
Femoral anteversion angle $\left(^{\circ}\right)$ & $20 \pm 11$ & & \\
\hline
\end{tabular}

Values are presented as mean \pm standard deviation or median (range).

$\mathrm{CEA}=$ centre-edge angle; ARO = acetabular roof obliquity; AcAV = acetabular anteversion angle.

\subsection{Statistical analysis}

JMP Software (version 13.0; SAS Institute, Cary, NC, USA) was used for all statistical analyses. Paired t-test or Wilcoxon's signedrank test was used to compare continuous variables before and after simulated osteotomy, depending on their distribution and homoscedasticity (Shapiro-Wilk's test and f-test). Student's t-test or Wilcoxon's rank-sum test was also used to compare continuous variables between two groups, as appropriate. Chi-square test was used to compare categorical variables between two groups. Receiver operator coefficient (ROC) curve was created to determine the cut-off value of preoperative anterior CEA that would predict residual anterolateral deficiency after lateral acetabular rotation to a lateral CEA of $30^{\circ}$. For all statistical analyses, the level of significance was set at $\mathrm{p}<0.05$.

\section{Results}

\subsection{Prevalence of residual anterolateral acetabular deficiency}

After lateral acetabular rotation to achieve a lateral CEA of $30^{\circ}$, the anterior CEA and AcAV increased whereas the posterior CEA, ARO, and Sharp angle decreased (Table 3). Based on the reference interval in the control group, 16 (19\%) hips were classified into the residual anterolateral deficiency group, 67 hips (79\%) into the

\section{Table 4}

Comparison of demographic and preoperative morphological parameters between the three groups.

\begin{tabular}{|c|c|c|c|c|}
\hline \multirow[t]{2}{*}{ Parameter } & \multicolumn{4}{|c|}{ Hip dysplasia group (85 patients [85 hips]) } \\
\hline & Residual deficiency (16 hips) & Normal coverage (67 hips) & Over coverage ( 2 hips) & p value ${ }^{a}$ \\
\hline \multicolumn{5}{|l|}{ Demographic parameters } \\
\hline Age (years) & $36 \pm 11$ & $38 \pm 11$ & $39 \pm 26$ & 0.740 \\
\hline Body mass index $\left(\mathrm{kg} / \mathrm{m}^{2}\right)$ & $22(19-31)$ & $22(17-35)$ & $25 \pm 5.2$ & 0.859 \\
\hline Laterality (left:right) & $9: 7$ & $26: 41$ & $0: 2$ & 0.217 \\
\hline Bilateral:unilateral & $6: 10$ & $25: 42$ & $0: 2$ & 0.555 \\
\hline \multicolumn{5}{|l|}{ Radiographic parameters } \\
\hline Lateral CEA $\left(^{\circ}\right)$ & $10 \pm 5.8$ & $17(1-24)$ & $20 \pm 0.3$ & 0.165 \\
\hline \multicolumn{5}{|l|}{ CT measurement parameters } \\
\hline Anterior CEA $\left({ }^{\circ}\right)$ & $32(9.7-39)$ & $43(12-58)$ & $62 \pm 1.6$ & $<0.001$ \\
\hline Lateral CEA $\left({ }^{\circ}\right)$ & $11 \pm 7.1$ & $15(2.5-22)$ & $18 \pm 2$ & 0.101 \\
\hline Posterior CEA $\left({ }^{\circ}\right)$ & $105 \pm 26$ & $97 \pm 17$ & $89 \pm 6.4$ & 0.177 \\
\hline ARO $\left(^{\circ}\right)$ & $24 \pm 6.8$ & $20(7.4-38)$ & $17 \pm 9$ & 0.189 \\
\hline $\operatorname{AcAV}\left({ }^{\circ}\right)$ & $29 \pm 6.5$ & $21(8.7-36)$ & $18 \pm 5.2$ & $<0.001$ \\
\hline Sharp angle $\left({ }^{\circ}\right)$ & $49 \pm 4$ & $49 \pm 3.6$ & $44 \pm 0.8$ & 0.687 \\
\hline Femoral head diameter $(\mathrm{mm})$ & $42 \pm 1.9$ & $43 \pm 1.2$ & $42 \pm 0.8$ & 0.634 \\
\hline Femoral anteversion angle $\left(^{\circ}\right)$ & $21 \pm 8.4$ & $20 \pm 11$ & $15 \pm 3.7$ & 0.833 \\
\hline
\end{tabular}

Values are presented as mean \pm standard deviation or median (range).

$\mathrm{CEA}=$ centre-edge angle; $\mathrm{ARO}=$ acetabular roof obliquity; AcAV = acetabular anteversion angle.

a Residual deficiency group versus normal coverage group. 


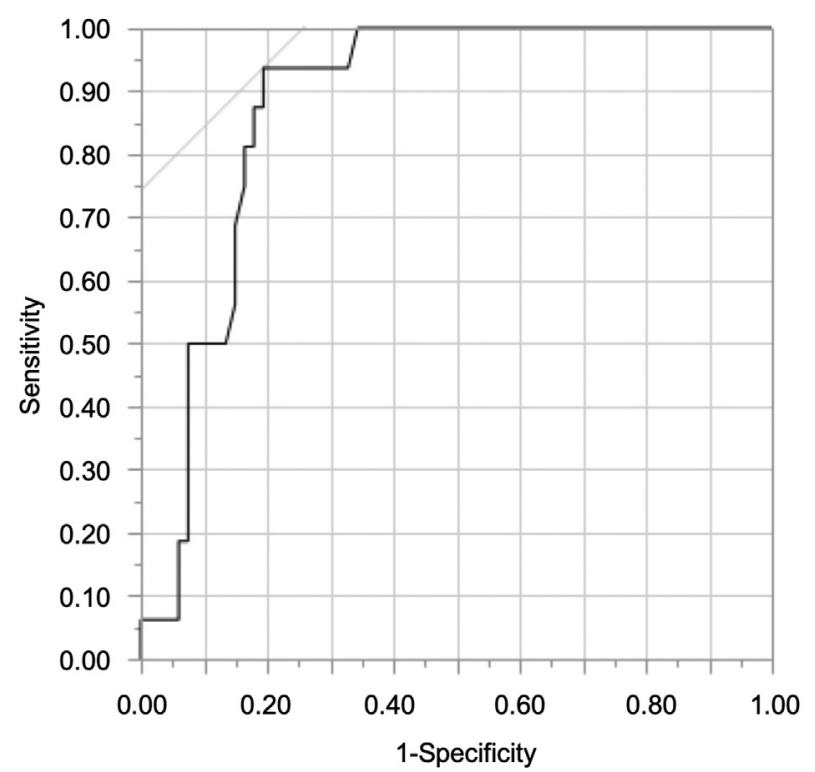

Fig. 4. The receiver operator coefficient curve analysis showed that the preoperative anterior CEA of $37^{\circ}$ could predict residual anterolateral deficiency after simulated osteotomy (sensitivity, $94 \%$; specificity, $81 \%$ ).
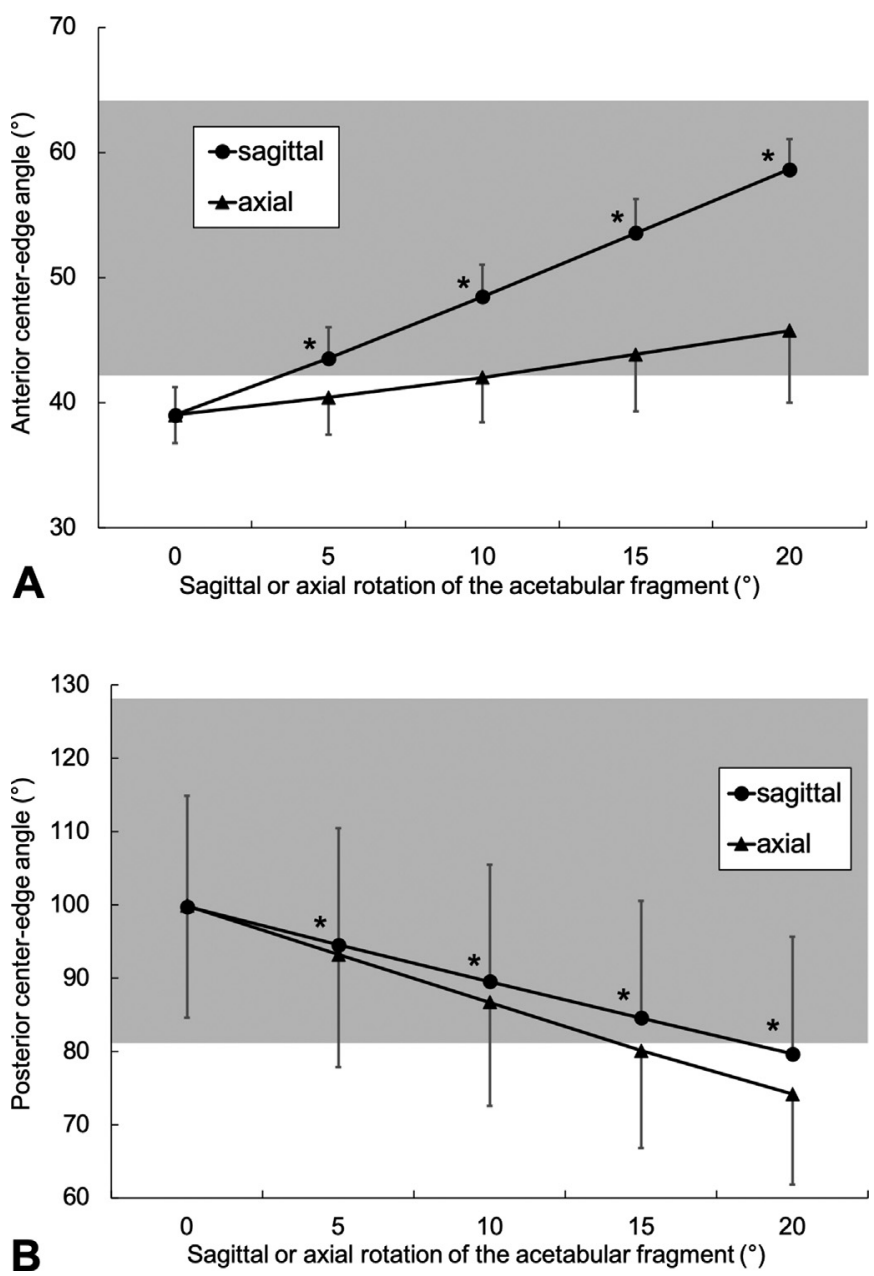

Fig. 5. A-B. Line graphs comparing the change of (A) the anterior centre-edge angle and (B) posterior centre-edge angle between the sagittal and axial rotations. Whiskers represent the standard errors. Grey area represents the reference interval. * $\mathrm{p}<0.05$, Student's t-test (sagittal rotation versus axial rotation).
Table 5

Comparison of the number of hips that achieved a normal anterior centre-edge angle between sagittal and axial rotations ( $\mathrm{N}=16 \mathrm{hips})$.

\begin{tabular}{llllll}
\hline & $0^{\circ}$ & $5^{\circ}$ & $10^{\circ}$ & $15^{\circ}$ & $20^{\circ}$ \\
\hline Sagittal rotation & $0(0)$ & $11(69)$ & $16(100)$ & $16(100)$ & $16(100)$ \\
Axial rotation & $0(0)$ & $6(38)$ & $11(69)$ & $12(75)$ & $12(75)$ \\
p value & n/a & 0.077 & 0.015 & 0.033 & 0.033 \\
\hline
\end{tabular}

Values are presented as the number of hips (\%).

$\mathrm{n} / \mathrm{a}=$ not applicable.

normal coverage group, and 2 hips (2.4\%) into the anterolateral overcoverage group (Table 4).

\subsection{Predictive factor for residual anterolateral deficiency}

No differences in demographic parameters and lateral CEA on plain radiograph were detected between the residual anterolateral deficiency and normal coverage groups (Table 4). However, hips in the former had greater preoperative AcAV and smaller preoperative anterior CEA than those in the latter (Table 4). ROC curve analysis showed that the preoperative anterior CEA of $37^{\circ}$ could predict residual anterolateral deficiency after simulated osteotomy (sensitivity, 94\%; specificity, 81\%) (Fig. 4).

\subsection{Comparison of the ability to normalise acetabular coverage between sagittal and axial rotations}

Mean anterior CEA gradually increased as the fragment was rotated sagittally or axially. The increase in anterior CEA was higher in the sagittal than in the axial rotation (Fig. 5A), and the total increase in anterior CEA at $20^{\circ}$ rotation was greater in the sagittal than in the axial rotation $\left(20^{\circ} \pm 0.9^{\circ}\right.$ vs. $\left.6.7^{\circ} \pm 4.7^{\circ}, \mathrm{p}<0.001\right)$. The number of hips that achieved normal anterior CEA was higher after sagittal rotation than after axial rotation at $10^{\circ}, 15^{\circ}$, and $20^{\circ}$ (Table 5). Normal anterior CEA was achieved in all hips after $10^{\circ}$, $15^{\circ}$, and $20^{\circ}$ sagittal rotation and in $75 \%$ of hips only after $20^{\circ}$ axial rotation (Table 5). In addition, mean posterior CEA gradually decreased as the fragment was rotated in either direction. The decrease in posterior CEA was higher in the axial rotation than in the sagittal rotation (Fig. $5 \mathrm{~B}$ ), and the total decrease in posterior $\mathrm{CEA}$ at $20^{\circ}$ rotation was smaller in the sagittal rotation than in the axial rotation $\left(-20^{\circ} \pm 1.5^{\circ}\right.$ vs. $\left.-26^{\circ} \pm 7.1^{\circ}, \mathrm{p}=0.008\right)$. The number of hips that achieved normal posterior CEA tended to be higher after sagittal rotation than after axial rotation at $10^{\circ}, 15^{\circ}$, and $20^{\circ}$; however, the difference was not statistically significant (Table 6). Sagittal rotation at $10^{\circ}$ had the highest number of hips with normal anterior and posterior CEA (13 hips, 81\%), which was followed by sagittal rotation at $15^{\circ}$ (10 hips, 63\%) (Table 7$)$. The fragment displacement was $7 \mathrm{~mm}$ at $10^{\circ}$ sagittal rotation and $10 \mathrm{~mm}$ at $15^{\circ}$ sagittal rotation, with a spherical osteotomy line with a radius of $40 \mathrm{~mm}$ around the femoral head center.

Table 6

Comparison of the number of hips that achieved a normal posterior centre-edge angle between sagittal and axial rotations ( $\mathrm{N}=16 \mathrm{hips})$.

\begin{tabular}{llllll}
\hline & $0^{\circ}$ & $5^{\circ}$ & $10^{\circ}$ & $15^{\circ}$ & $20^{\circ}$ \\
\hline Sagittal rotation & $14(88)$ & $13(81)$ & $13(81)$ & $10(63)$ & $8(50)$ \\
Axial rotation & $14(88)$ & $13(81)$ & $11(69)$ & $8(50)$ & $6(38)$ \\
p values & 1.000 & 1.000 & 0.414 & 0.476 & 0.476 \\
\hline
\end{tabular}

Values are presented as the number of hips (\%). 
Table 7

Comparison of the number of hips that achieved both normal anterior and posterior centre-edge angles between sagittal and axial rotations ( $\mathrm{N}=16$ hips).

\begin{tabular}{llllll}
\hline & $0^{\circ}$ & $5^{\circ}$ & $10^{\circ}$ & $15^{\circ}$ & $20^{\circ}$ \\
\hline Sagittal rotation & $0(0)$ & $8(50)$ & $13(81)$ & $10(63)$ & $8(50)$ \\
Axial rotation & $0(0)$ & $3(19)$ & $7(44)$ & $6(38)$ & $5(31)$ \\
p values & n/a & 0.063 & 0.029 & 0.157 & 0.28 \\
\hline
\end{tabular}

Values are presented as the number of hips (\%).

$\mathrm{n} / \mathrm{a}=$ not applicable.

\section{Discussion}

In this study, we found that lateral rotation of the acetabular fragment is effective in correcting anterolateral deficiency as well as lateral coverage. Most hips (79\%) achieved normal anterolateral coverage after lateral rotation of the acetabular fragment; however, $19 \%$ of the hips had residual anterolateral deficiency. Xuyi et al. [27] also reported that anterior CEA was insufficient in some patients when the acetabular fragment was rotated laterally to the normal range in simulated periacetabular osteotomy. The shearing stress forces and overload are concentrated on the anterolateral acetabular rim; thus, the intra-articular pathology generally originates from the anterolateral labro-chondral junction of the acetabulum $[8,9]$. Therefore, if they remain in anterolateral deficiency, these hips are predisposed to postoperative development of hip OA. Akiho et al. [10] demonstrated that anterior CEA is a predictor of OA progression, in addition to lateral CEA and acetabular roof obliquity. Thus, additional acetabular correction should be applied to these patients to manage residual anterolateral deficiency.

This study revealed the characteristics of patients at risk of residual anterolateral deficiency after lateral acetabular coverage correction. We assume that an anterior CEA of $<37^{\circ}$ is a useful index for predicting residual anterolateral acetabular deficiency after correcting lateral acetabular deficiency. While no differences in lateral CEA were found between the residual deficiency group and normal coverage group, the hips in the residual deficiency group had greater AcAV and smaller anterior CEA than those in the normal coverage group. Plain radiographs are limited in their ability to assess and characterise the acetabular morphology [28,29]. Mimura et al. [28] reported that the prevalence of acetabular dysplasia in a multiplanar evaluation is greater than that in a coronal evaluation. Moreover, Nepple et al. [7] reported that acetabular deficiency varies and that three different patterns of acetabular deficiency may occur in patients with hip dysplasia. Thus, a morphological assessment in the coronal plane may overlook a possible acetabular wall deficiency in the sagittal and axial planes, which could in turn compromise adequate acetabular corrections. A precise understanding of 3D characterization of bony anatomy is particularly important for an accurate surgical correction of the underlying multiplanar deformities [7].

Acetabular correction in periacetabular osteotomy commonly consists of lateral rotation, anterior rotation, medialization of the hip center, and version correction [6,11,26]. During TOA, the first step of acetabular reorientation is lateral rotation to normalize lateral coverage, and the second step is anterior rotation to normalize anterolateral coverage, if necessary [17]. This process is consistent with the acetabular reorientation during periacetabular osteotomy described by Troelsen et al. [11]. They suggested that extremely minimal anterior movements are needed to create a sufficient anterior coverage. In this study, we confirmed that additional anterior sagittal rotation is more effective than posterior axial rotation in achieving a normal anterior CEA and that $10^{\circ}-15^{\circ}$ anterior rotation is appropriate to retain the posterior CEA. Unnecessary anterior rotation of the acetabular fragment should be avoided because decreased posterior coverage or excessive anterior coverage could result in poor osteotomy outcomes $[3,12,14,15]$.

This study has several limitations. First, the simulated osteotomy could not completely reproduce a real osteotomy. Asphericity of the femoral head and acetabulum, joint instability, and movement of the rotational center in hip dysplasia were not considered. The acetabular coverage was analyzed without considering individual differences in functional pelvic tilt, hip range of motion, and postoperative impingement. Although these factors would not affect the finding of this study that anterior sagittal rotation was more effective than posterior axial direction in achieving a normal anterior CEA, further investigations are needed to determine the effect of acetabular correction on the joint instability, range of motion, and impingement. Second, we excluded patients with severe hip dysplasia (lateral CEA $<0^{\circ}$ ) who are candidates for periacetabular osteotomy. The acetabular weight-bearing area of these hips is often insufficient to achieve normal acetabular coverage. Therefore, surgeons should aware that normalizing anterolateral coverage can exacerbate the posterior deficiency in these patients [27]. Third, we did not assess changes in lateral CEA that could be caused by anterior rotation of the acetabular fragment. However, a previous study have shown that there is no relevant changes in lateral CEA with varying pelvic orientation [30]. Thus, we believe that changes in lateral CEA caused by sagittal rotation of the acetabular fragment do not affect the results of this study.

\section{Conclusions}

Normal anterolateral coverage was achieved in $79 \%$ of patients after lateral rotation of the acetabular fragment to achieve a lateral CEA of $30^{\circ}$ in simulated osteotomy. However, $19 \%$ of the patients had residual anterolateral deficiency, and their hips had a greater acetabular anteversion angle and smaller anterior CEA preoperatively. Close attention should be paid to patients with a preoperative anterior $\mathrm{CEA}<37^{\circ}$ because lateral rotation of the acetabular fragment may be insufficient to correct anterolateral acetabular deficiency. Moreover, in these patients, additional $10^{\circ}-15^{\circ}$ anterior rotation of the acetabular fragment in the sagittal direction is recommended to achieve a sufficient anterolateral acetabular coverage while retaining the posterolateral coverage.

\section{Author contributions}

M. Iwamoto: Designed the study, Collected the data, Analyzed the data, Wrote the manuscript.

M. Fujii: Study co-ordinator, Designed the study, Enrolled the patients, Collected the data, Analyzed the data, Wrote the manuscript.

K. Komiyama: Collected the data, Analyzed the data.

Y. Sakemi: Collected the data, Analyzed the data.

K. Shiomoto: Collected the data, Analyzed the data.

K. Kitamura: Collected the data, Analyzed the data.

R. Yamaguchi: Collected the data, Analyzed the data.

Y. Nakashima: Created the concept, Designed the study, Enrolled the patients, Wrote the manuscript.

\section{Funding statement}

This work was supported by a Grant-in-Aid for Scientific Research from the Japan Society for the Promotion of Science, Grant Number JP18K09109. 


\section{Ethical committee approval}

Each author certifies that his or her institution approved the human protocol for this investigation and that all investigation was conducted in conformity with ethical principles of research.

\section{Declaration of Competing Interest}

Each author certifies that he or she has no commercial associations that might pose a conflict of interest in connection with the submitted article.

\section{Acknowledgement}

None.

\section{References}

[1] Clohisy JC, Schutz AL, St John L, Schoenecker PL, Wright RW. Periacetabular osteotomy: a systematic literature review. Clin Orthop Relat Res 2009 Aug;467(8):2041-52.

[2] Yasunaga Y, Yamasaki T, Ochi M. Patient selection criteria for periacetabular osteotomy or rotational acetabular osteotomy. Clin Orthop Relat Res 2012 Dec:470(12):3342-54.

[3] Steppacher SD, Tannast M, Ganz R, Siebenrock KA. Mean 20-year followup of Bernese periacetabular osteotomy. Clin Orthop Relat Res 2008 Jul;466(7): $1633-44$.

[4] Ganz R, Leunig M. Morphological variations of residual hip dysplasia in the adult. Hip Int 2007;17(Suppl 5):22-8

[5] Murphy SB, Kijewski PK, Millis MB, Harless A. Acetabular dysplasia in the adolescent and young adult. Clin Orthop Relat Res 1990 Dec;261:214-23.

[6] Trousdale RT. Acetabular osteotomy: indications and results. Clin Orthop Relat Res 2004 Dec;429:182-7.

[7] Nepple JJ, Wells J, Ross JR, Bedi A, Schoenecker PL, Clohisy JC. Three patterns of acetabular deficiency are common in young adult patients with acetabular dysplasia. Clin Orthop Relat Res 2017 Apr;475(4):1037-44.

[8] Henak CR, Abraham CL, Anderson AE, Maas SA, Ellis BJ, Peters CL, Weiss JA. Patient-specific analysis of cartilage and labrum mechanics in human hips with acetabular dysplasia. Osteoarthritis Cartilage 2014 Feb;22(2):210-7.

[9] Fujii M, Nakashima Y, Noguchi Y, Yamamoto T, Motomura G, Hamai S Iwamoto Y. Factors associated with severity of intra-articular lesions in patients with severe hip dysplasia. Arthroscopy 2016 Aug;32(8):1581-9.

[10] Akiho S, Yamamoto T, Kinoshita K, Matsunaga A, Ishii S, Ishimatsu T. The utility of false-profile radiographs for the detection of osteoarthritis progression in acetabular dysplasia. JBJS Open Access 2017 Oct 5;2(4):e0023.

[11] Troelsen A, Elmengaard B, Søballe K. A new minimally invasive transsartorial approach for periacetabular osteotomy. J Bone Joint Surg Am 2008 Mar;90(3): 493-8.

[12] Hipp JA, Sugano N, Millis MB, Murphy SB. Planning acetabular redirection osteotomies based on joint contact pressures. Clin Orthop Relat Res 1999 Jul:364:134-43.

[13] Rab GT. Lateral acetabular rotation improves anterior hip subluxation. Clin Orthop Relat Res 2007 Mar;456:170-5.
[14] Myers SR, Eijer H, Ganz R. Anterior femoroacetabular impingement after periacetabular osteotomy. Clin Orthop Relat Res 1999 Jun;363: 93-9.

[15] Kiyama T, Naito M, Shiramizu K, Shinoda T. Postoperative acetabular retroversion causes posterior osteoarthritis of the hip. Int Orthop 2009 Jun;33(3): 625-31.

[16] Nishio A. Transposition osteotomy of the acetabulum for the treatment of congenital dislocation of the hip. Nippon Seikeigeka Gakkai Zassi 1956;30: 482-4 (in Japanese).

[17] Fujii M, Nakashima Y, Noguchi Y, Yamamoto T, Mawatari T, Motomura G, Iwamoto Y. Effect of intra-articular lesions on the outcome of periacetabular osteotomy in patients with symptomatic hip dysplasia. J Bone Joint Surg Br 2011 Nov;93(11):1449-56.

[18] Hamai S, Kohno Y, Hara D, Shiomoto K, Akiyama M, Fukushi J-I, Motomura G, Ikemura S, Fujii M, Nakashima Y. Minimum 10-year clinical outcomes after periacetabular osteotomy for advanced osteoarthritis due to hip dysplasia. Orthopedics 2018 Sep;41(5):300-5.

[19] Wiberg G. Studies on dysplastic acetabula and congenital subluxation of the hip joint: with special reference to the complication of osteo-arthritis. Acta Chir Scand 1939;83(Suppl.58):5-135.

[20] Tönnis D, Legal H. Congenital dysplasia and dislocation of the hip in children and adults. Berlin and New York: Springer-Verlag; 1987. p. 165-71.

[21] Crowe JF, Mani VJ, Ranawat CS. Total hip replacement in congenital dislocation and dysplasia of the hip. J Bone Joint Surg Am 1979 Jan;61(1): $15-23$.

[22] Hara D, Nakashima Y, Hamai S, Higaki H, Ikebe S, Shimoto T, Hirata M, Kanazawa M, Kohno Y, Iwamoto Y. Kinematic analysis of healthy hips during weight-bearing activities by 3D-to-2D model-to-image registration technique. BioMed Res Int 2014;2014:457573.

[23] Lewinnek GE, Lewis JL, Tarr R, Compere CL, Zimmerman JR. Dislocations after total hip-replacement arthroplasties. J Bone Joint Surg Am 1978 Mar;60(2): 217-20.

[24] Kohno Y, Nakashima Y, Akiyama M, Fujii M, Iwamoto Y. Does native combined anteversion influence pain onset in patients with dysplastic hips? Clin Orthop Relat Res 2015 Dec;473(12):3716-22.

[25] Miyasaka D, Sakai Y, Ibuchi S, Suzuki H, Imai N, Endo N. Sex- and age-specific differences in femoral head coverage and acetabular morphology among healthy subjects-derivation of normal ranges and thresholds for abnormality. Skeletal Radiol 2017 Apr;46(4):523-31.

[26] Hamada H, Takao M, Nakahara I, Sakai T, Nishii T, Sugano N. Hip range-ofmotion (ROM) is less than normal after rotational acetabular osteotomy for developmental dysplasia of the hip: a simulated ROM analysis. J Orthop Res Feb 2016;34(2):217-23.

[27] Xuyi W, Jianping P, Junfeng Z, Chao S, Yimin C, Xiaodong C. Application of three-dimensional computerised tomography reconstruction and image processing technology in individual operation design of developmental dysplasia of the hip patients. Int Orthop 2016 Feb;40(2):255-65.

[28] Mimura T, Mori K, Kitagawa M, Ueki M, Furuya Y, Kawasaki T, Imai S. Multiplanar evaluation of radiological findings associated with acetabular dysplasia and investigation of its prevalence in an Asian population: a CTbased study. BMC Muscoskel Disord 2017 Jan;18(1):18-50.

[29] Larson CM, Moreau-Gaudry A, Kelly BT, Byrd JW, Tonetti J, Lavallee S, Chabanas L, Barrier G, Bedi A. Are normal hips being labeled as pathologic? A CT-based method for defining normal acetabular coverage. Clin Orthop Relat Res 2015 Apr:473(4):1247-54.

[30] Tannast M, Hanke MS, Zheng G, Steppacher SD, Siebenrock KA. What are the radiographic reference values for acetabular under- and overcoverage? Clin Orthop Relat Res 2015 Apr;473(4):1255-66. 